\title{
PARENTAL PARTIALITY AND FUTURE CHILDREN
}

\author{
Thomas Douglas
}

$\prod$ ARENTS ARE TYPICALLY partial to their own children. They typically treat their own children more favorably, on certain dimensions, than other similarly placed individuals. For example, most parents invest more emotional and financial resources in sheltering, nourishing, educating, and entertaining their children than they invest in others who are equally in need of these goods, and would benefit equally from them. Moreover, most parents take themselves to be justified in engaging in such partiality, and most philosophical theorists of partiality agree.

Less commonly noted is that parents can also be partial toward their future children - children who will, but do not yet, exist. They can, for example, set aside resources for their own future children in preference to investing them in others who could make similar use of those goods. Consider:

$A \& B$ plan to, and will in fact, have a child together, but they have not yet conceived. They win $£ 10,000$ in the lottery and are considering whether to set it aside for their future child's education or donate it to a charity that helps to provide education to impoverished children in Africa. They decide to set it aside for their future child; they simply care more about their child's education.

Like parental partiality, such "pre-parental partiality" plausibly stands in need of justification. ${ }^{1}$ For one thing, it is unclear whether and how pre-parental partiality_like partiality more generally_can be reconciled with the plausible

1 It might be denied that there is any partiality in this case if the child $A \& B$ will have (i) would not have existed had they not engaged in the partiality, and (ii) is not benefitted by being brought into existence. Perhaps partiality necessarily involves benefitting the object of the partiality. However, regardless of whether the case of $A \& B$ is aptly described as a case of partiality, it bears sufficient structural similarities to paradigmatic cases of partiality that it seems worthwhile to consider how justifications for partiality might bear upon it, which is what I will do here. I will continue to refer to cases like that of $A \& B$ as cases of partiality, though nothing will turn on whether they are aptly described. 
thought that everyone matters equally. ${ }^{2}$ For another, pre-parental partiality can have troubling distributive effects. ${ }^{3}$ For instance, if economically well-off parents direct their economic resources preferentially to their own future children, those children are likely to wind up better off, economically, than the (present or future) children of parents who are less well off, or who allocate their economic resources less partially.

It thus seems legitimate to demand a moral justification for pre-parental partiality. However, unlike parental partiality, pre-parental partiality has not enjoyed the sort of philosophical attention that might be expected either to furnish or to foreclose such justification. Though the possibility of pre-parental partiality has been noted in ethical discussions of reproductive technologies, its justifiability has attracted little comment. ${ }^{4}$

So what should we make of pre-parental partiality? What moral assessment does it merit? Were we to take commonsense morality as our guide, we would, I think, be obliged to take a highly permissive stance: commonsense morality grants parents substantial leeway to be partial to their current children, and it is, I think, just as permissive of pre-parental partiality. However, I will argue that philosophical justifications of parental partiality do not carry over so easily to the pre-parenthood case. Insofar as the reasons in favor of the two kinds of partiality are established through appeal to existing philosophical justifications, the reasons in favor of pre-parental partiality will typically be weaker than reasons in favor of parental partiality. Thus, either reasons in favor of pre-parental partiality are indeed typically weaker than reasons in favor of parental partiality-suggesting, contrary to common sense, that pre-parental partiality will be permissible in a narrower range of circumstances - or the literature on partiality is importantly incomplete: it does not capture all of the reasons in favor of partiality in play in these cases. ${ }^{5}$

2 See Pettit and Goodin, "The Possibility of Special Duties”; Keller, Partiality, ch. 1. Keller calls this the "puzzle of partiality."

3 For discussion of distributive concerns regarding parental and other varieties of partiality toward existing people, see Scheffler, "Relationships and Responsibilities"; Brighouse and Swift, "Legitimate Parental Partiality."

4 For discussion of pre-parental partiality in relation to reproductive technologies, see, for example, Lillehammer, "Reproduction, Partiality and the Non-Identity Problem"; Elster, "Procreative Beneficence"; Douglas and Devolder, "Procreative Altruism: Beyond Individualism in Reproductive Selection"; Petersen, "On the Partiality of Procreative Beneficence"; Lewandowski, "Parents, Special Obligations and Reproductive Genetics." For discussion of the justifiability of pre-parental partiality, see Lillehammer, "Reproduction, Partiality and the Non-Identity Problem"; Lewandowski, "Parents, Special Obligations and Reproductive Genetics."

5 I assume here that the reasons against partiality are similar in parental and pre-parental cas- 
Throughout, I will limit myself to cases in which, not only does the child in question not yet exist, she has also not yet been conceived. ${ }^{6}$ These are, I think, the cases in which the task of justifying partiality is most challenging. I henceforth use the terms "pre-parent" and "prospective parent" interchangeably to refer to pre-conception prospective parents.

\section{THREE TYPES OF JUSTIFICATION}

In identifying candidate justifications for pre-parental partiality, I will draw on the literature on the justification of parental partiality, and that on the justification of partiality more generally. In those literatures, three broad types of justification can be found.

Justifications of the first type-telic justifications—appeal to some value that is (expectably) realized by the partiality. ${ }^{7}$ In the case of partiality between family members, friends, or romantic partners, the value invoked is often love. ${ }^{8} \mathrm{John}$ Cottingham's justification of "philophilic partialism" - partiality within loving relationships - provides a clear example:

The justification of philophilic partialism is ... extremely simple. If I give

es. In both, the chief concern is that partiality could have unjust or otherwise undesirable distributive effects, and I see no reason to suppose that this problem would be greater in the one case than the other.

6 Some will hold that the point at which the child comes into existence is the point of conception, and I do not mean to contradict that view here.

7 I henceforth omit the "(expectably)." Influential examples of telic justifications have been offered by John Cottingham and by Harry Brighouse and Adam Swift. See Cottingham, "Partiality, Favouritism and Morality"; Brighouse and Swift, "Legitimate Parental Partiality" and Family Values. Scheffler ("Relationships and Responsibilities") defends a justification according to which partiality contributes (in his account, constitutively) to a relationship that the agent of the partiality has net, noninstrumental reasons to value. This justification is equivalent to a telic justification if we have net, noninstrumental reasons to value something just in case the thing in fact has value. However, even if Scheffler's justification is not equivalent to a telic justification it has, I believe, the same implications for the justification of pre-parental partiality. Thus, I will not consider it separately.

8 Such love-based justifications for parental partiality should not be confused with justifications for love. The latter, if successful, justify parental partiality, insofar as such partiality is a constituent of love. Moreover, they may derive some of their justificatory force from an appeal to love. For example, Niko Kolodny holds that part of the justification for loving someone is that one has had a loving relationship with that person in the past; see Kolodny, "Love as Valuing a Relationship." However, justifications for love-and thus for any partiality that is a constituent of love-need not attribute any normative role to (other aspects of) love in justifying the partiality. They may, for example, invoke some third factor that directly justifies both the partiality and the (other aspects of) love. 
no extra weight to the fact that this is my love, my friend, my spouse, my child, if I assess these people's needs purely on their merits (in such a way as an impartial observer might do), then that special concern which constitutes the essence of love and friendship will be eliminated. Partiality to loved ones is justified because it is an essential ingredient of one of the highest human goods. ${ }^{9}$

The thought here is that partiality is justified by virtue of its contribution to realizing valuable love, or some particular kind of valuable love. On Cottingham's picture, the contribution of partiality to love is constitutive; treating a person partially is part of what it is to love that person. But we can equally imagine a view on which partiality is justified by its causal contribution to the development of love. Perhaps partiality tends to elicit feelings of affection for the agent of the partiality, and perhaps these feelings partly constitute love.

Justifications for partiality of a second type-deontic justifications-invoke some relationship between the agent and recipient of the partiality, and hold this to provide non-value-based (henceforth, "deontic") reasons of partiality. It is plausible, for instance, that a contractual relationship could play this role; that you and I have agreed to share my lottery winnings may give me a reason to treat you partially in disbursing those winnings, and that reason is plausibly (though not uncontroversially) independent of any value that will be realized by my upholding the agreement. ${ }^{10}$ Contractual relationships are, however, not the only relationships that have been thought to play such a role. For example, some have held that being in a (certain kind of) loving relationship with another may give one a deontic reason to treat that other partially. ${ }^{11}$ Similarly, some have held that being responsible for creating a person may give one such a reason, regardless of whether it implies the existence of an implicit contract. ${ }^{12}$

Finally, what I will call hybrid justifications of partiality hold that reasons of partiality are ultimately telic reasons - reasons to realize value-but these reasons are enabled or strengthened by the relationship between the agent and re-

9 Cottingham, "Partiality, Favouritism and Morality," 369.

10 I am here entertaining the possibility that some reasons are not reasons to realize value, however I do not mean to commit myself to this view. If there are no such reasons, so much the worse for this class of justifications for partiality.

11 See, for an example of this approach, Jeske, "Families, Friends, and Special Obligations."

12 See, for this approach and variants thereof, Rakowski, Equal Justice, 153-55; Steiner and Vallentyne, "Libertarian Theories of Intergenerational Justice”; Olsaretti, "Liberal Equality and the Moral Status of Parent-Child Relationships"; Ferracioli, "Procreative-Parenting, Love's Reasons and the Demands of Morality." Anca Gheaus argues that it is gestating a person that generates reasons of partiality; see Gheaus, "The Right to Parent One’s Biological Baby.” 
cipient of the partial treatment. Simon Keller defends a view of this kind. ${ }^{13} \mathrm{He}$ argues that reasons of partiality are reasons to promote the good of the recipient of the partiality. Thus, for example, your child's value is the source of your reasons to treat your child partially. But of course, other children are also valuableperhaps equally so-yet you do not have similarly strong reasons in relation to them. This, on Keller's view, is because features of your relationship with your child enable your child's value to generate special reasons for you, while no similar enabling condition is present in relation to other children.

Philip Pettit and Robert Goodin's justification for partiality within special relationships can also be understood as a hybrid justification. ${ }^{14}$ On their view, duties of partiality are a function of both value and responsibility; they are duties to realize states of affairs that are valuable and for which one is responsible. Though Pettit and Goodin do not put it in these terms, we can think of one's responsibility for a state of affairs as enabling the value of that state of affairs to generate (especially strong) reasons.

It might be thought that there is a fourth class of justifications that needs to be considered: "two-level" justifications, according to which people have reasons to treat some others partially because they would be assigned such reasons under the optimal scheme for distributing our more general, agent-neutral moral obligations across people. ${ }^{15}$ However, even if reasons of partiality have this deep source, they will have a surface structure that falls into one of the categories that I mentioned above. Thus, we do not need to consider such two-level justifications for partiality as a separate category. We can simply acknowledge that justifications of the three varieties I have mentioned-telic, deontic, and hybridmay themselves be subsumed within a two-level justification of this sort. Similar thoughts apply to sophisticated forms of consequentialist justification, according to which one has most reason to do whatever act has the agent-neutrally best consequences, but one may also have most reason to adopt a decision-making procedure that involves deciding as if one had different reasons, perhaps including reasons of partiality. ${ }^{16}$ We can regard telic, deontic, and hybrid justifications as three different models of the reasons that one would, under the decision-making procedure one ought to adopt, take oneself to have.

13 See, Keller, Partiality.

14 Pettit and Goodin, "The Possibility of Special Duties." See also Goodin, "What Is So Special about Our Fellow Countrymen?"

15 For an example of this approach, see Goodin, "What Is So Special about Our Fellow Countrymen?"

16 See, for the classic statement of this sort of view, Railton, "Alienation, Consequentialism, and the Demands of Morality." 
The important point is that, regardless of whether these three different types of justification for partiality are subsumed under a deeper agent-neutral justification, they have different implications for the justification of pre-parental partiality. In the next two sections, I consider whether deontic justifications might be able to justify pre-parental partiality, either directly (section 2) or indirectly (section 3 ). In section 4, I turn to consider telic justifications. I do not explicitly examine hybrid justifications for pre-parental partiality, but I hope it will be clear how my arguments would apply to such justifications. I believe that they face all of the problems that I raise for telic justifications, as well as some of those that I raise for deontic justifications.

\section{DEONTIC JUSTIFICATIONS}

It may seem that, if being in a certain kind of relationship with someone is to give one a deontic reason to be partial, that relationship must already exist. Consider: if being in a contractual relationship with someone is to give one a reason to fulfill the terms of the contract—and thus, perhaps, a reason to be partial—one must already have formed the contract. The mere fact that you and I will agree to send one another comments on our papers does not yet give me any reason to send you such comments. At least, it does not give me the ordinary kind of contractual reason to do so. (I return in the next section to consider the possibility that it might give me some other kind of reason.) This raises the question: do any of the relationships that have been thought to provide reasons of partiality already exist between a pre-parent and her future child? ${ }^{17}$

Above, I mentioned three kinds of relationship that have been thought to generate deontic reasons of partiality: contractual relationships, procreative relationships, and loving relationships. It seems clear that pre-parents do not already stand in a contractual relationship with their future child. Perhaps parents have normally agreed — explicitly or implicitly— to provide certain kinds of support to their existing children. However, the most plausible points at which that contract is formed are the point of adoption (in the case of adopted children), the point at which the choice is made not to adopt a child out, or the point of voluntary conception. Whichever of these points one chooses, pre-parents-that is, preconception prospective parents-have not yet formed the contract.

It is even clearer that preconception prospective parents do not already stand in a procreative relationship with their future child; the process of creation has not yet begun. But could a prospective parent already stand in a loving relation-

17 Niko Kolodny raises a restricted version of this question in "Which Relationships Justify Partiality?" 65-66. 
ship with her future child? This is perhaps more plausible. After all, diachronic love with people who do not currently exist does seem possible. It seems possible for a person to love her long-lost grandparent, for instance.

Nevertheless, we can doubt that a pre-parent can enjoy a loving relationship with her future child. For a loving relationship to exist between two individuals, it is plausibly necessary that at least one party to the relationship love the other. ${ }^{18}$ But clearly a child cannot love his parent before the child exists. And we might also doubt whether a parent can love a child before the child exists. This is because loving someone plausibly requires a kind of attachment to a particular individual. We can see this by considering relationships that seem otherwise to mimic love but lack this attachment. Imagine a parent who pours affection on her child, is highly partial toward her child, derives great pleasure from the flourishing of that child, but is completely indifferent to whether that child is replaced by another. We would not want to say that this parent loves her child, and the obvious way of accounting for this would be to invoke the view that love requires attachment to a particular individual.

It is, however, difficult to see how a prospective parent could have any attachment to her future child as a particular individual. First, in typical cases, the identity of the future child could be influenced by the partial action whose justification is in question or by other choices subsequently made by the parents or others. There is thus a sense in which, prior to that action, the identity of the future child has not yet been fixed: it remains within the sphere of human choice. Second, even in cases where the identity of the future child has been fixed, in the sense that it will not be altered by the parents' or anyone else's choices, the prospective parents will not have any information about their particular future child that would allow them to fix on that child as a particular individual. ${ }^{19}$ Indeed, they will typically know nothing that uniquely picks out the particular future

I use "love" here and throughout to refer only to what is sometimes called "interpersonal love," as distinct from the kind of love that a person can have for an inanimate object.

19

On one influential account of love, David Velleman's, love consists not in the presence of any positive attachment, but rather in the letting down of certain emotional defenses. Love "arrests our tendencies toward emotional self-protection from another person" ("Love as a Moral Emotion," 361). Note, however, that Velleman does still think of love as directed toward a particular individual who is viewed as incomparable to and irreplaceable by others (see especially 364-68). Thus love, on Velleman's account, still requires that the lover can latch on to the object of his love as a particular person. Indeed, Velleman makes this explicit, noting that "unless we actually see a person in the human being confronting us, we won't be moved to love; and we can see the person only by seeing him in or through his empirical persona" (371). 
child that they will have, distinguishing that child from other possible children that they might have had. ${ }^{20}$

In any case, even if prospective parents can form such an attachment, they typically do not. This can be seen by considering cases in which a third party acts so as to alter the identity of the future child. Suppose that Arama and Bram are due to undergo a fertility treatment in which one of Arama's eggs will be fertilized by one of Bram's sperm in vitro. You phone Bram just as he is about to leave for the fertility clinic to give the sperm sample. As a result, he gives the sample fifteen minutes later than would otherwise have been the case, with the result that Arama's egg is fertilized by a different sperm. You have altered the identity of Arama and Bram's future child, yet it seems doubtful that they would feel that they have suffered any kind of loss. They would regard their new, post-phonecall future child as a perfect replacement for the pre-phone-call child. This indicates that they had no attachment to the particular future child that they would otherwise have had.

I have been suggesting that a loving relationship normally does not exist between a pre-parent and her future child because neither the pre-parent nor the future child loves the other. However, even if a loving relationship does exist between a pre-parent and her future child, there are reasons to doubt whether this love could be as normatively significant as parent-child love-reasons to doubt, that is, that it could generate similarly strong deontic reasons of partiality. It is plausible that at least some of the normative significance of parent-child love derives from a feature of the parent-child relationship that a relationship between a pre-parent and her future child cannot have: intimacy.

Parent-child relationships typically involve intimacy—by which I mean repeated positive, personal interactions that make each vulnerable to the other. Moreover, the intimacy of paradigmatic parent-child relationships, and the closest romantic relationships and friendships, is plausibly part of what gives these loving relationships their peculiarly great normative force.

To see this, consider a case in which a previously intimate relationship loses its intimacy. Suppose Cedric and Danele were close friends who saw each oth-

20 I am not here claiming, contra Harry Frankfurt, that one must appreciate the value of another, or have significant information about their personal characteristics, in order to love that other. I am claiming only that one has to have enough information to fix on the other as a particular person. See Frankfurt, The Reasons of Love, esp. 39. I am also not suggesting that there are never cases in which pre-parents would have enough information to fix on a particular child. We could think here of a case in which the pre-parents have already selected the egg and sperm that will be used to create their future child, and already committed to using a genetic technology to "design in" some unique genetic characteristics to that child. I thank an anonymous reviewer for pressing me to consider cases of this sort. 
er and engaged in highly personal and revealing conversations multiple times per day, but who then became separated from one another, and completely lost contact for a number of years, though their deepest positive attitudes toward one another remained unchanged. Several years after this separation, Cedric and Danele happen upon each other on the street, and Cedric asks Danele to do him a significant favor-to spend the weekend helping him move apartments, for example. It is plausible that some kind of loving relationship still exists between the two and that this gives Danele some reason to help Cedric with his move. However, it is also plausible that this reason is significantly weaker than it would have been had Cedric asked for the help at a time when the two were still in regular and close contact. This suggests that the loss of what I am calling intimacy has diminished the normative significance of the friendship. It is, moreover, possible to give a plausible explanation for why the loss of intimacy causes this loss of significance: intimacy arguably produces a web of mutual expectations and implicit commitments that gives the parties to the intimate relationship special reasons to help and care for one another.

These thoughts indicate that, even if it is possible for a loving relationship to exist between a pre-parent and her future child, this relationship will be in one respect less normatively significant than paradigmatic parent-child relationships, since a pre-parent clearly cannot enjoy intimacy with her future child. Since it is difficult to see any countervailing respect in which pre-parent/future-child love, if it can exist, would be more normatively significant than parent-child love, this suggests that it will, overall, generate less strong deontic reasons.

I have been arguing that contractual, procreative, and loving relationships either fail to establish deontic reasons of pre-parental partiality, or typically establish only weaker deontic reasons in support of such partiality than in support of parental partiality. Are there other relationships that might generate deontic reasons of pre-parental partiality that are just as strong as our reasons for parental partiality? Perhaps there are. After all, a pre-parent and her future child do stand in some significant relationships to one another. In cases of genetic parenthood, they stand in a rather close genetic relationship. They also stand in the relationship of extended family co-membership. It might be thought that one or other of these relationships generates deontic reasons to be partial. Moreover, since these same relationships exist between a current parent and her existing child, it might seem that these relationships will generate reasons of partiality that are equally strong in the parental and pre-parental cases.

It is, however, not plausible that an appeal to these relationships can fully account for the reasons in favor of ordinary parental partiality. To see this, note that genetic relationships and co-memberships of social groups are sometimes 
invoked to justify partiality between members of the same racial, species, or national groups. And though many would argue that some partiality between the members of national and species groups is justified by the existence of these relationships, it is not plausible that the reasons to engage in such forms of partiality are as strong as those to engage in parental partiality. Similarly, some might hold that genetic parents who are not social parents have reasons of partiality in respect of their genetic children, and that family co-members whose relationship is more distant than a parent-child relationship have reasons of partiality in respect of each other, but it is not at all plausible that these reasons are as strong as the reasons of partiality that social parents have with respect to their social children. This suggests that there are further reasons to engage in parental partiality-reasons above and beyond those provided by genetic relationships and social group (including family) co-membership. Plausibly, some of these reasons are based on the existence of a contractual, procreative, or loving relationship in parental cases. But, if my arguments above are sound, these reasons do not obtain in pre-parental cases, or are less forceful in such cases than in cases of parental partiality. Thus, even if the reasons of partiality generated by genetic relationships and social group co-membership are equally strong in pre-parental and parental cases, we remain without any basis for thinking that reasons of pre-parental partiality are, all things considered, as strong as our reasons of parental partiality.

\section{ENSURING MORAL COMPLIANCE}

I suggested above that contractual reasons of the ordinary kind only obtain once the contractual relationship is in place, and likewise for deontic reasons deriving from procreative or loving relationships. But perhaps these relationships could generate other kinds of deontic reasons that obtain even before the relevant relationship exists. Let us again take the case of contractual reasons as illustrative. Though ordinary contractual reasons only obtain once the contract has been formed, those reasons plausibly give rise to derivative reasons that obtain in advance of the contract. Suppose I know that I will agree to give you comments on your draft paper. An ordinary contractual reason to give you these comments is not yet in place, but it is plausible that some derivative reasons are already in place. I may already have reasons not to do things that make me less likely to live up to my agreement. For example, I may have reasons not to promise others comments on their papers, knowing that I will not be able to comment on more than one paper. ${ }^{21}$ More generally, it might seem that we each have moral reasons

21 The existence of these derivative reasons need not depend on my already having the 
not to prevent our compliance with our future contractual reasons, and, indeed, with our future moral reasons more generally. This raises the question of whether pre-parental partiality might be justified on the ground that failing to engage in such partiality could be expected to prevent one's compliance with one's future reasons of parental partiality, whatever the source of those future reasons.

Let us begin to explore this possible justification for pre-parental partiality by seeing how it plays out in the case of $A \& B$, with which I began. In the original version of the case, $A \& B$ set aside their lottery winnings for the education of their future child rather than donating them to an African educational charity. Suppose they had instead taken the opposite course, donating their winnings to the African charity. Would they then have prevented their future compliance with reasons of partiality? ?2 $^{22}$

One reason to doubt that they would becomes apparent when we attend to the nature of the reasons of partiality that $A \& B$ will have once their child exists. We can distinguish two importantly different possibilities. One possibility is that $A \& B$ 's reasons of partiality, once their child exists, will be reasons to (expectably) confer some benefit (or prevent some harm) that is independent of $A \& B$ 's motives for conferring (preventing) it. ${ }^{23}$ For example, perhaps $A \& B$ will have reason to confer some given level of education on their future child. Call reasons of this sort reasons to benefit.

A second possibility is that $A \& B$ 's reasons of partiality are reasons to give certain consideration or significance to their child in their decision making about whom to benefit and to what degree. For example, perhaps $A \& B$ will have reason to give their child greater consideration than other children in deciding how to allocate their resources. Call reasons of this sort reasons to consider. Unlike reasons to benefit, which are reasons to bring about particular states of affairs, reasons to consider are reasons to deploy particular procedures in deciding which states of affairs to bring about. ${ }^{24}$ I believe that at least some of the reasons of

intention to form the contract. It may be enough that the contract will be formed, or that I reasonably believe it will be formed.

22 Note that, if "reason to" implies "can," then, in preventing future parental partiality, $A \& B$ may have prevented themselves from falling under reasons of partiality, rather than preventing their compliance with those reasons. In this case, we will need to understand their putative pre-parental reasons not as reasons to ensure their compliance with reasons that they will have to engage in parental partiality, but as reasons to ensure their compliance with reasons that they would have had had they acted otherwise.

This benefit could be absolute, or relative to the benefit enjoyed by others.

24 It is plausible that some reasons are neither simply reasons to benefit nor simply reasons to consider, but are rather mixed reasons: for example, reasons to bring about certain benefits for certain reasons, or reasons to bring about benefits that constitute benefits in part in 
partiality that parents have with respect to their children are reasons to consider rather than reasons to benefit.

Suppose that Edith is a moderately well-off parent who believes that parental partiality is unjustified and strives to allocate no more time, effort, or money to her own children than to other equally needy children with whom she has contact. However, as it happens, she very rarely comes into contact with other children, and when she does, they are typically less needy than her own child. Thus, she ends up allocating far more time, effort, and money to her own child than to others; in fact, the share of her resources that go to her own child relative to others is typical for other similarly well-off parents. Edith's neighbor Femke is similarly well-off, and is also a parent. Like Edith, Femke allocates to her child a share of her time, effort, and money that is typical of similarly well-off parents. However, she does this for the usual reason: because she gives priority to the interests of her own child in her practical deliberation.

It seems clear that there is something defective about Edith's parenting that is not defective about Femke's parenting. Yet both parents apparently benefit their children to the same degree, both in absolute terms and relative to other children. The most straightforward way to explain the defect in Edith's parenting is, I believe, to suppose that, in addition to reasons to benefit their children, parents have reasons to give certain consideration to their children in practical decision making. The problem with Edith's parenting is that she does not give sufficient consideration to her own child and thus fails to fully comply with these reasons. ${ }^{25}$

This has important implications for the justification of pre-parental partiality in the case of $A \& B$. We were supposing that $A \& B$ 's pre-parental partiality in setting aside their lottery winnings might be justified by its tendency to promote compliance with their future reasons of parental partiality. But to the extent that $A \& B$ 's future reasons of parental partiality will be reasons to consider rather than reasons to benefit, it is not clear how this justification could succeed, for $A \& B$ 's setting aside the $£ 10,000$ is plausibly irrelevant to the degree of consideration that they will subsequently give to their child in their decision making. Had $A \& B$ donated their lottery winnings to the African charity rather than setting them aside, they would have restricted the maximum possible educational benefit that they could subsequently confer on their future child. But it is not at all clear that they would have diminished the degree of consideration that they will

virtue of the reasons for which they are conferred. However, for my purposes here, we can ignore reasons of these kinds.

25 As a conceptual matter, it also seems to me doubtful that we could aptly describe Edith as treating her child partially; partiality necessarily involves giving special consideration to the target of the partiality. 
give to their child in allocating whatever resources they will in fact have. They will be just as free, and plausibly at least as likely, to give special consideration to their future child in distributing their wealth if they give the $£ 10,000$ away; they will simply have less wealth to distribute.

All of this suggests that $A \& B$ 's derivative reasons to engage in pre-parental partiality will be less powerful than their later reasons to engage in parental partiality. Once $A \& B$ have their child, they will plausibly have both reasons to benefit and reasons to consider in respect of that child, but only the reasons to benefit give rise to derivative reasons to engage in pre-parental partiality.

There are, no doubt, some cases in which both reasons to benefit and reasons to consider generate derivative reasons to engage in pre-parental partiality, since pre-parental partiality contributes to future compliance with both sorts of reason. Suppose that Gael expects to have, and love, a child in the future. He is considering whether to cultivate a disposition to be highly partial to his future child, or a disposition to be an unusually impartial parent-one who gives little more weight to his own child than to others. If Gael chooses to cultivate the impartial disposition, he will diminish his future compliance with reasons of partiality regardless of whether those reasons are reasons to benefit or reasons to consider. This is a rather special case, however. In typical cases where pre-parental partiality is an option, failing to engage in that partiality will not frustrate compliance with future reasons to consider. Thus, reasons of pre-parental partiality will, on the present approach, typically be weaker, all things considered, than the reasons of parental partiality from which they derive. ${ }^{26}$

\section{TELIC JUSTIFICATIONS}

Let us turn now to consider telic justifications. As candidate justifications for pre-parental partiality, telic justifications have an advantage over deontic justifications: the values they invoke can directly generate reasons even if the values do not yet obtain. On telic justifications, it is enough that the partial treatment will (expectably) realize the value at some point in the future. A telic justification for pre-parental partiality could succeed even if the value(s) invoked will obtain only once the child has come into existence.

26 Of course, reasons of pre-parental partiality could still be strong even if they derive only from reasons to benefit. After all, some may hold that reasons to benefit are powerful in parental cases-perhaps sufficiently strong to, on their own, establish obligations to engage in parental partiality. Nevertheless, the result that reasons of pre-parental partiality are typically weaker than reasons of parental partiality is significant, since it suggests that pre-parental partiality will be permissible, and obligatory, in a narrower range of cases than parental partiality. 
Telic justifications can be broadly split into two classes. Justifications of the first sort invoke some particular value and maintain that this value can best, or only, be realized through partiality. Cottingham's abovementioned justification, according to which partiality constitutively contributes to love, exemplifies this approach. By contrast, justifications of a second kind invoke no special value. Rather, they try to show that, in treating certain individuals near and dear to us favorably, we will generally produce more of whatever is good for people. This is because we are better placed to advance the interests of those near and dear to us than to advance the interests of others. ${ }^{27}$ At least part of the story here is that we are normally in a particularly good epistemic position with respect to those near and dear to us: we are particularly good at identifying their interests.

Telic justifications of the second sort do not seem promising as a basis for establishing reasons of pre-parental partiality as strong as those of parental partiality. This is because at least part of the case for partiality on this view-the part that invokes epistemic considerations-does not carry over in full from the parental to the pre-parental case. Though parents typically are in a strong position to know what will advance the interests of their existing children, they are normally in a much weaker epistemic position with respect to their future children. Though pre-parents will normally know some general facts about the kind of social environment their future children are likely to occupy, and may be able to make some reasonable assumptions about the kinds of genetic predispositions they are likely to possess, they will not have the sort of detailed knowledge regarding a child's individual needs and proclivities that is typical of parents.

Let us focus, then, on telic justifications of the first sort-justifications invoking particular values that can best or only be realized through partiality. As we have seen, one value sometimes invoked in such justifications is love. Another is the value of completing (or advancing) parental projects. ${ }^{28}$ It might seem that there is generally value in advancing one's projects, at least when those projects are not morally prohibited, and many people have projects that can be most effectively pursued through parental partiality.

Each of these values may, it seems to me, justify some pre-parental partiality. Consider forms of pre-parental partiality that help secure a stable and rich social environment for the future child. It is quite plausible that such partiality helps foster forms of emotional intelligence in the child that are conducive to the development of parent-child love. It is also plausible that some forms of pre-pa-

See, for an example of this approach, Jackson, "Decision-Theoretic Consequentialism and the Nearest and Dearest Objection." 
rental partiality contribute significantly to the advancement of the pre-parents' projects. Suppose, for instance, that a couple have adopted the project of raising a child who has every chance of becoming a music star, or at least of fulfilling her potential for such. In order to most effectively pursue this project, these pre-parents may need to set aside significant funds for private music tuition before the child is conceived.

Still, there are reasons to think that love- and project-based telic justifications will provide weaker support for pre-parental partiality than for parental partiality. Consider first love-based telic justifications. It is plausible that one way in which parental partiality typically contributes to love is by expressing parental attachment to the child. The expression of such attachment may be partly constitutive of love, but even if it is not, it plausibly contributes causally to love. I have already argued, however, that pre-parents typically do not have any attachment to their particular future child, so it is not clear how pre-parental partiality could express such an attachment. This suggests that, in at least this one respect, pre-parental partiality will be less conducive to the realization of love than parental partiality.

Consider next project-based telic justifications. It is plausible that our reasons to advance our personal projects are generally weaker in the early stages of the project than they are in the later stages. Thus, for example, we would normally think that a person has weaker project-based reasons to advance her project of writing a novel when she is only one page in than when she only has one chapter left to write. In the early stages, we would think there is little to be lost in sacrificing the project in order to, say, adopt another one; in the later stages, we might think that any such substitution of projects would involve a significant loss. This point is relevant to the case of pre-parental partiality since pre-parents are typically only in the early stages of their parental project. This suggests that their project-based reasons will typically be weaker than those of parents.

I contend, then, that both love- and project-based telic reasons of partiality will typically be weaker in pre-parental cases than in parental cases. However, even if this is not so, it is doubtful that an appeal to such reasons could show that, all things considered, the reasons that support parental partiality are normally as strong as those supporting parental partiality. This is because, as with the appeals to genetic relationships and social group co-membership discussed in section 2, it is doubtful that either of these justifications can fully account for parents' reasons to treat their children partially: it is doubtful that the only reasons of parental partiality are project-based and love-based telic reasons. This can be seen by considering a case in which, due to estrangement, a parent has no prospect of realizing a loving relationship with her child, and the child plays no 
role in the parent's projects. ${ }^{29}$ It seems hardly plausible that such a parent would have no reasons of partiality in respect of her child in such a case. We would, for example, surely still think that, were the estranged child to fall into desperate need, the parent would have some special reason to help him. There seem, then, to be reasons of parental partiality besides telic reasons to realize love or advance parental projects. If, say, those further reasons include the reasons invoked by deontic contract- or procreation-based justifications, and my arguments above are sound, then these other reasons do not fully carry over to pre-parental cases. In that case, the conclusion that reasons of pre-parental partiality are overall weaker than those of parental partiality will stand.

\section{CONCLUSIONS}

I have now considered three kinds of justification that might be offered for pre-parental partiality.

Justifications of the first kind appeal directly to deontic reasons that arise from certain kinds of relationships. I argued that the relationships normally invoked to establish these reasons - contractual, procreative, and loving relationships-do not obtain between prospective parents and their future children, or obtain only in a less normatively significant form. By contrast, the genetic and familial relationships that do exist between prospective parents and their future children generate only weak deontic reasons of partiality, and do not fully account for reasons of parental partiality.

Justifications of the second kind hold that prospective parents will have reasons to engage in parental partiality once their child exists. They seek to justify pre-parental partiality as a means to ensuring compliance with those reasons. I argued that such derivative reasons of pre-parental partiality will typically be weaker than the reasons of parental partiality from which they derive: in most cases, pre-parental partiality will not increase compliance with some reasons of parental partiality - those that are reasons to consider.

Finally, on justifications of the third kind-telic justifications-partiality is justified by the values that it (expectably) realizes. I argued that the values most commonly invoked in support of parental partiality-the values of project advancement and love-will typically provide weaker support for pre-parental partiality than for parental partiality. I also questioned whether these telic reasons exhaust our reasons in favor of parental partiality.

The upshot of my arguments is this: existing justifications for partiality

29 For further reasons to doubt that project-based reasons exhaust reasons of parental partiality, see Keller, Partiality, ch. 2. 
typically establish weaker reasons in support of pre-parental partiality than in support of parental partiality. Thus, either these existing justifications do not fully account for our reasons of parental partiality, or our reasons to engage in pre-parental partiality are indeed typically weaker than our reasons to engage in parental partiality. If the latter, we can expect that, contrary to common sense, pre-parental partiality will be morally permitted, and indeed morally required, in a narrower range of circumstances than parental partiality. ${ }^{30}$

University of Oxford thomas.douglas@philosophy.ox.ac.uk

\section{REFERENCES}

Brighouse, Harry, and Adam Swift. Family Values: The Ethics of Parent-Child Relationships. Princeton: Princeton University Press, 2014.

_. "Legitimate Parental Partiality." Philosophy and Public Affairs 37, no. 1 (Winter 2009): 43-80.

Cottingham, John. "Partiality, Favouritism and Morality." Philosophical Quarterly 36, no. 144 (July 1986): 357-73.

Douglas, Thomas, and Katrien Devolder. "Procreative Altruism: Beyond Individualism in Reproductive Selection." Journal of Medicine and Philosophy 38 , no. 4 (August 2013): 400-19.

Elster, Jakob. “Procreative Beneficence - Cui Bono?” Bioethics 25, no. 9 (November 2011): $482-88$.

Ferracioli, Laura. "Procreative-Parenting, Love's Reasons and the Demands of Morality." Philosophical Quarterly (forthcoming).

Frankfurt, Harry. The Reasons of Love. Princeton: Princeton University Press, 2004.

Gheaus, Anca. “The Right to Parent One's Biological Baby.” Journal of Political Philosophy 20, no. 4 (December 2012): 432-55.

Goodin, Robert E. "What Is So Special about Our Fellow Countrymen?" Ethics 98, no. 4 (July 1988): 663-86.

Jackson, Frank. "Decision-Theoretic Consequentialism and the Nearest and Dearest Objection.” Ethics 101, no. 3 (April 1991): 461-82.

30 I would like to thank Ben Lange, Roger Crisp, Serena Olsaretti, Areti Theofilopoulou, and audiences in Ghent and Belfast for their comments on earlier versions of this paper. I thank the Uehiro Foundation on Ethics and Education for its funding. 
Jeske, Diane. "Families, Friends, and Special Obligations." Canadian Journal of Philosophy 28, no. 4 (December 1998): 527-55.

Keller, Simon. Partiality. Princeton: Princeton University Press, 2013.

Kolodny, Niko. "Love as Valuing a Relationship." Philosophical Review 112, no. 2 (April 2003): 135-89.

_ . "Which Relationships Justify Partiality? The Case of Parents and Children." Philosophy and Public Affairs 38, no. 1 (Winter 2010): 37-75.

Lewandowski, Wojciech. "Parents, Special Obligations and Reproductive Genetics." In The Ethics of Reproductive Genetics: Between Utility, Principles, and Virtues, edited by Marta Soniewicka, 67-80. Dordrecht: Springer, 2018.

Lillehammer, Hallvard. "Reproduction, Partiality and the Non-Identity Problem." In Harming Future Persons, edited by Melinda A. Roberts and David T. Wasserman, 231-48. Dordrecht: Springer, 2009.

Olsaretti, Serena. "Liberal Equality and the Moral Status of Parent-Child Relationships." In Oxford Studies in Political Philosophy, vol. 3, edited by David Sobel, Peter Vallentyne, and Steven Wall, 58-83. Oxford: Oxford University Press, 2017.

Petersen, Thomas Søbirk. "On the Partiality of Procreative Beneficence: A Critical Note." Journal of Medical Ethics 41, no. 9 (September 2015): 771-74.

Pettit, Philip, and Robert Goodin. "The Possibility of Special Duties." Canadian Journal of Philosophy 16, no. 4 (December 1986): 651-76.

Railton, Peter. "Alienation, Consequentialism, and the Demands of Morality." Philosophy and Public Affairs 13, no. 2 (Spring 1984): 134-71.

Rakowski, Eric. Equal Justice. Oxford: Clarendon Press, 1991.

Scheffler, Samuel. "Relationships and Responsibilities." Philosophy and Public Affairs 26, no. 3 (Summer 1997): 189-209

Steiner, Hillel, and Peter Vallentyne. "Libertarian Theories of Intergenerational Justice." In Intergenerational Justice, edited by Axel Gosseries and Lukas $\mathrm{H}$. Meyer, 50-76. Oxford: Oxford University Press, 2009.

Stroud, Sarah. "Permissible Partiality, Projects, and Plural Agency." In Partiality and Impartiality: Morality, Special Relationships, and the Wider World, edited by Brian Feltham and John Cottingham, 131-49. Oxford: Oxford University Press, 2010.

Velleman, J. David. “Love as a Moral Emotion.” Ethics 109, no. 2 (January 1999): 338-74.

Williams, Bernard. "Persons, Character and Morality." In Moral Luck: Philosophical Papers 1973-1980, 1-19. Cambridge: Cambridge University Press, 1981.

Wolf, Susan. "Morality and Partiality." Philosophical Perspectives 6 (1992):243-59. 